Saudi Journal of Humanities and Social Sciences

Abbreviated Key Title: Saudi J Humanities Soc Sci

ISSN 2415-6256 (Print) | ISSN 2415-6248 (Online)

Scholars Middle East Publishers, Dubai, United Arab Emirates

Journal homepage: $\underline{\text { http://scholarsmepub.com/sihss/ }}$

Original Research Article

\title{
Measuring Life Stress of Accounting Students
}

\author{
Dr. Chaiyaset Promsri* \\ Rajamangala University of Technology Phra Nakhon, Bangkok, Thailand
}

DOI: $\underline{10.36348 / \text { sjhss.2019.v04i11.001 }}$ | Received: 28.10.2019| Accepted: 04.11.2019| Published: 10.11 .2019

*Corresponding author: Dr. Chaiyaset Promsri

Email: chaiyaset.p@rmutp.ac.th

\section{Abstract}

This study was undertaken to investigate the level of life stress among college students, and to compare differences in life stress level between different groups of time online spent daily. Samples of 191 accounting students registered in strategic management course at a selected public university in Bangkok, Thailand agreed to complete the online questionnaire through Google platform. Results indicated that the overall level of life stress among accounting students was at a medium level $(M=2.91$, S.D. $=.704)$. Analysis of this study also demonstrated that the most frequently stress relief approach used by this group of students was "consulting with a reliable person" whereas "seeing a psychiatrist" was reported as the least frequently stress relief method used. Additionally, a Kruskal-Wallis H test showed that there was a statistically significant difference in level of life stress between the different groups of time online spent daily, $\chi^{2}(2)=11.410, p=.003$, with a mean rank life stress score of 82.13 for less than 5 hours group, 86.03 for 5-8 hours group, and 113.29 for more than 8 hours group, respectively.

Keywords: Stress, Life stress, Accounting students, College students.

Copyright @ 2019: This is an open-access article distributed under the terms of the Creative Commons Attribution license which permits unrestricted use, distribution, and reproduction in any medium for non-commercial use (NonCommercial, or CC-BY-NC) provided the original author and source are credited.

\section{INTRODUCTION}

Stress is perceived as any incident that makes pressure on a person's ability to handle leading to emotional or physical strains, which can occur in individuals' daily lives [1]. Stress is viewed as negative behavioral and psychological responses occurred when an individual attempted to deal with stressors [2]. Levels of stress are fluctuated depending on an individual's sensitivity of a certain event $[3,4]$.

Although stress happens to everyone, college students are a group of people considered to have a lot of stress. Major factors caused college students' stress are physical and mental, family, social, financial, and academic [5]. As most of college students are an adolescence who is in a stage of human development in between childhood and maturity and challenged by many stressors to develop their identity and quality to become a high quality person in the society $[6,7]$. Earning a high level of academic performance deems very important and is viewed as the essential factor to enter in the prestigious workplace. This expectation and aspiration can cause them some stress. Numerous studies attempted to scrutinize causes of stress among college students in the past decades [8]. Most of these studies found similar sources of stress, which consist of examinations, assignments, and parents' expectations $[3,4]$.

Several studies have made an effort to scrutinize association between stress and academic performance, causes of stress and stress management strategies practiced by students, and comparison of stress levels between males and females or undergraduate and graduate students. However, many of these prior studies tended to focus on academic stress rather than life stress. In addition, a study on life success among college students in Thai context is very little and needed more exploration [9]. As a result, this present study aimed to examine level of life stress among college students in Thai context.

\section{LITERATURE REVIEWS}

The emergence of stress is due to the combination of internal and external strains exceeds a person's capability to manage that specific situation. Students viewed as an adolescence experience different forms and sources of stress, which can deteriorate their health, relationship, and academic performance [7]. Numerous studies on stress among college students have been introduced in prior literatures in different contexts, which mostly found the similar sources and 
causes of stress among students. Examples of these literatures were systematically reviewed to see the gap of the work in this area.

Buksh, Shahzad, and Nisa [1], tried to investigate the symptoms of stress, causes of stress, and recommend strategies to cope with stress through 200 students in one Islamic university in Pakistan. Load of study and assignments were reported as the main causes of stress. Participants disclosed that entertainment and leisure activities such as watching TV or movies and music listening were strategies used to diminish stress. This study suggested that related activities to subject matters should be developed as part of the curriculum and instructions.

Devi and Mohan [6] gathered data from 200 students in two different colleges in Kerala, India through the questionnaire. This study measured students' stress in 5 major areas including academic stress, social stress, family stress, emotional stress, and financial stress. Academic problems were found to be the main stressor of academic stress rated by students. In addition, this study found that lack of family support was the major stressor of family factor viewed by respondents. Moreover, lack of self-esteem was reported as the major emotional stressor.

Veena and Shastri [3] investigated the sources of stress among college students in India. A total of 656 students from both pure science and applied science concentrations were gathered for data collection through a Stressful Life Events Inventory - Student form developed by Rao in 1986. Results found that applied science undergraduate students were more stressful than pure science students. Also, the major stress reported by students was educational stress, which examination and change of instructor were rated as the most important academic stressor.

Hemamalini, Ashok, and Sasikala [10] examined the impacts of stress on students' academic performance, well-being, and general lifestyle. Samples were collected from post graduate students by using the questionnaire. Findings revealed that students perceived faculty supports, examination, and lack of understanding the subject matter as the major stressors leading to more stressful in academic success. In addition, this study tried to explore the difference in perceived stress between males and females, but no statistically significant difference was found.

Prifti \& Rapti [11] collected data from 1,502 students in Albania through the questionnaire to explore the correlation between stress, attachment style, and academic performance. This study found the relationship between stress and attachment. This research filled the gap of the literatures in this area in the different context.
Yikealo, Yemane, and Karvinen [12] studied level of academic and environmental stress among students in college of education in EIT. Data were collected from 107 students in all levels of college of education excepted freshmen. This study showed the medium level of academic and environmental stress among students. Findings indicated no statistically significant difference in terms of gender and students' GPA.

According to literature reviews, various studies attempted to examine relationship between stress and academic performance, causes of stress and stress management strategies practiced by students, and comparison of stress levels between males and females or undergraduate and graduate students. However, many of these prior studies placed their emphasis on academic stress rather than other stress. Although some research tried to include major stress factors to determine stress levels and academic success among students, an investigation of life stress among college students was diminutive. Therefore, this study sought to examine level of life stress among college students. Also, as technology has become the most important part of people lives, it was quite interesting to explore the relationship between time online spent daily and stress. As the past research of Swedish scholars found that too much time online could cause stress and depression. These reasons led to two major questions of this study as follows:

Q1: What was the overall life stress level of college students who participated in this study? Q2: Was there a statistically significant difference in life stress among distinctive groups of time online spent daily?

\section{METHODOLOGY}

This descriptive study attempted to examine the level of life stress among college students. Samples were drawn from 209 accounting students who enrolled in "strategic management course" at a selected government university in Bangkok, Thailand. Only 191 students agreed to participate in this study by filling out the online questionnaire on the Google platform and returned it with completion. Life stress was measured by modifying a life stressful scale proposed by Robbins, DeCenzo, and Coulter [13]. This scale contained an 8item of 5-point rating scale ranging from 1 (strongly disagree) to 5 (strongly agree). This scale was modified and translated into Thai language by Promsri [9] in which validity and reliability was conducted. In this present study, validity and reliability was redone to ensure the quality of the scale measurement. The Cronbach's alpha score of 0.774 was acceptable to use this scale to assess college students' life stress. In addition, respondents were inquired to answer the ways frequently used to relieve stress. This item was a checklist in which participants can check more than one stress relief approach (multiple responses) including playing game, hangout with friends or family, posting stress 
problem online, consulting a reliable person, seeing a psychiatrist, physical exercise, and drinking. Also, participants were asked to answer the frequency of time online spent daily based on three separate answers: less than 5 hours, 5-8 hours, and more than 8 hours. To explore level of respondents' life stress, descriptive statistics were used. Kruskal-Wallis test was used to examine if there was a statistically significant difference in time online spent daily among respondents. The reason to use this non-parametric test instead of One-Way ANOVA was due to the small sample size of one group, which was below 30 units.

\section{RESULTS}

Findings revealed that the majority of respondents were female $(86.9 \%)$. The vast of their average monthly income was below THB5,000 (approximately \$150). Nearly 60 percent of participants had 4-6 members in their family $(59.7 \%)$. More than a half of them spent their time online about 5-8 hours a day. Table-1 displayed the level of life stress among accounting students. The total mean score of students' life stress level was in a moderate level $(\mathrm{M}=2.91$, S.D. $=.704)$. Specifically, the highest mean score of life stress was item\#1 "I often overwhelmed to do things and I have no time to do them" $(\mathrm{M}=3.85$, S.D. $=.992)$ whereas item\#6 "often, I feel worried about financial sources of my incomes" was reported as the lowest mean score $(\mathrm{M}=1.88$, S.D. $=1.21)$.

Table-1: Alpha Score, Mean, and Standard Deviation for Life Stress ( $n=191)$

\begin{tabular}{|c|c|c|c|c|}
\hline Items & Alpha Score & Mean & S.D. & Rank \\
\hline 1. I often feel overwhelmed to do things and I have no time to do them. & .765 & 3.85 & .992 & 1 \\
\hline 2. I feel pressured by someone else to make an outstanding job. & .758 & 3.52 & 1.13 & 3 \\
\hline 3. I find myself to have a lot of assignments and tasks to complete. & .723 & 3.18 & 1.08 & 4 \\
\hline 4. Quite often, I am not sure what my family's expectation on me. & .748 & 2.64 & 1.27 & 5 \\
\hline 5. I am worried about my expenses. & .747 & 3.83 & 1.15 & 2 \\
\hline 6. Often, I feel worried about financial sources of my incomes. & .757 & 1.88 & 1.21 & 8 \\
\hline 7. I find that I make many people disappointed because of my commitment. & .739 & 2.17 & 1.11 & 7 \\
\hline 8. Often, I have conflict with my family members. & .758 & 2.17 & 1.07 & 6 \\
\hline Total & .774 & 2.91 & .704 & \\
\hline
\end{tabular}

Also, respondents were asked to report the stress relief approach usually practiced while having stress. Table- 2 demonstrated that the most frequently stress relief approach used by this group of students was "consulting with a reliable person" $(29.9 \%)$ followed by "playing game" (29.1\%) and "hangout with friends or family" (27.8\%). The least frequently stress relief method used was "see a psychiatrist" $(0.4 \%)$.

Table-2: Multiple Responses of Stress Relief Approaches Frequently Used by Students

\begin{tabular}{|c|c|c|}
\hline Stress Relief Approaches & Frequency & Percentage \\
\hline Play Game & 134 & $29.1 \%$ \\
\hline Hangout & 128 & $27.8 \%$ \\
\hline Post Online & 17 & $3.7 \%$ \\
\hline Consulting & 138 & $29.9 \%$ \\
\hline See a Psychiatrist & 2 & $0.4 \%$ \\
\hline Physical Exercise & 35 & $7.6 \%$ \\
\hline Drinking & 7 & $1.5 \%$ \\
\hline Total & 461 & $100 \%$ \\
\hline
\end{tabular}

To determine if there was a statistically significant difference in life stress level between the different groups of time spent online on a daily basis, Kruskal-Wallis $\mathrm{H}$ test was computed. Results of a Kruskal-Wallis $\mathrm{H}$ test indicated that there was a statistically significant difference in level of life stress between the different groups of time online spent daily, $\chi^{2}(2)=11.410, p=.003$, with a mean rank life stress score of 82.13 for less than 5 hours group, 86.03 for 5-8 hours group, and 113.29 for more than 8 hours group.

\section{CONCLUSION, DISCUSSIONS, AND RECOMMENDATIONS}

This present study aimed at measuring the level of life stress among accounting students at a selected public university. Findings revealed that the overall level of students' life stress was at a moderate level, which could be interpreted that this group of students perceived themselves to have stress, but they still could handle it properly. Also, this study found that the most frequently stress relief approach among this group of students was "consulting with a reliable person." This finding supported the previous studies relating to stress, which described that an individual feel relieved from stress when having the specific interaction with a person who truly understands their feelings and problems $[14,15]$. It was remarkable to find that a few students chose alcohol used or drinking as the way to relieve their stress. This study also showed a statistically significant difference in life stress level between the different groups of time spent online 
on a daily basis, according to a Kruskal-Wallis $\mathrm{H}$ test. This supported the prior study of Swedish researchers who found that too much time spent online in everyday could lead to stress, sleeping disorders, and depression [16].

Like other studies, this study had some limitations. Firstly, samples were solely gathered from accounting students at a selected public university. The next study should extend the samples to students in other majors and colleges to examine level of life stress among those students. Secondly, the scale measurement employed in this study was a self-report questionnaire, which may have had some biases. The other approaches of assessing stress should be conducted to genuinely determine level of life stress. Also, this scale was a short-version that attempted to measure life stress among students only. Other stresses should be evaluated separately in the further study such as academic stress. Lastly, the variable used to identify the effect on life stress was limited to time online spent daily. Thus, the further study should add more variables to see the relationship between those additional variables and life stress.

As respondents felt overwhelmed to do things and had no time to do them, the university should create "stress management" and "time management" program to help students understand how to relieve their stress in an appropriate way when having this kind of feeling. According to this study's finding, students are recommended reducing their time online to release stress and other physical problems. They also should be educated that sharing their stress with someone whom they can rely on is one of the good stress relief approaches they can do.

\section{ACKNOWLEDGEMENT}

I am very thankful to Rajamangala University of Technology Phra Nakhon for publication sponsorship and facility supports.

\section{REFERENCES}

1. Bukhsh, Q., Shahzad, A., \& Nisa, M. (2011). A study of learning stress and stress management strategies of the students of postgraduate level: A case study of Islamia University of Bahawalpur, Pakistan. Procedia - Social and Behavioral Sciences, 30, 182-186.

2. Bernstein, D. A, Penner, L. A, Stewart, A. C., \& Roy, E. J. (2008). Psychology (8th ed.). Boston, NY: Houghton Mifflin Company.

3. Veena, N., \& Shastri, S. (2016). Stress and academic performance. The International Journal of Indian Psychology, 3(3/4), 71-82.

4. Jain, G., \& Singhai, M. (2018). Academic stress amongst students: a review of literature. Prestige
e-Journal of Management and Research, 5(1), 5867.

5. Mazumdar, H., Gogoi, D., Buragohain, L., \& Haloi, N. (2012). A comparative study on stress and its contributing factors among the graduate and Post-graduate students. Advances in Applied Science Research, 3(1), 399-406

6. Devi, R. S., \& Mohan, S. (2015). A study on stress and its effects on college students. International Journal of Scientific Engineering and Applied Science, 1(7), 58-67.

7. Aafreen, M., Priya, V., \& Gayathri, R. (2018). Effect of stress on academic performance of students in different streams. Drug Invention Today, 10(9), 1776-1780.

8. Saqib, M., \& Rehman, K. U. (2018). Impact of stress on students academic performance at secondary school level at District Vehari. International Journal of Learning and Development, 8(1), 84-93.

9. Promsri, C. (2018). The influence of external locus of control on life stress: Evidence from graduate students in Thailand. International Journal of Social Sciences Perspectives, 3(1), 38-41.

10. Hemamalini, R., Ashok, V., \& Sasikala, V. (2018). A study on stress management and its impact among students. International Journal of Academic Research in Economics and Management Sciences, 7(3), 101-110.

11. Prifti, L., \& Rapti, E. (2018). The relationship between attachment, stress and academic success in Albanian students. Journal of Educational and Social Research, 8(2), 53-60.

12. Yikealo, D., Yemane, B., \& Karvinen, I. (2018). The level of academic and environmental atress among college students: A case in the College of Education. Open Journal of Social Sciences, 6, 4057.

13. Robbin, S. P., DeCenzo, D. A., \& Coulter, M. (2015). Fundamentals of management: Essential concepts and applications $\left(9^{\text {th }}\right.$ ed.). New York, NY: Prentice-Hall.

14. Townsend, S. S. M., Kim, H. S., \& Mesquita, B. (2013). Are you feeling what I'm feeling? Emotional similarity buffers stress. Retrieved from http://spp.sagepub.com/content/early/2013/12/16/1 948550613511499.abstract

15. USC Marshall School of Business. (2014). Two stressed people equals less stress. Retrieved from http://www.eurekalert.org/pub_releases/201401/umso-tsp012914.php

16. Thomée, S., Härenstam, A., \& Hagberg, M. (2011). Mobile phone use and stress, sleep disturbances, and symptoms of depression among young adults - a prospective cohort study. Retrieved from https://bmcpublichealth.biomedcentral.com/article s/10.1186/1471-2458-11-66. 